\title{
Financial Market and Inflation
}

\author{
Yuqing $Q i^{1}$ \\ ${ }^{1}$ School of Economics, Central University of Finance and Economics, Beijing, China; \\ Correspondence: Yuqing Qi, School of Economics, Central University of Finance and Economics, Beijing, \\ 102200, China. Tel: 86-158-1014-3308. E-mail: YuqingQ@ hotmail.com
}

Received: April 13, 2020

Accepted: May 3, 2020

Online Published: May 28, 2020

doi:10.5539/ijef.v12n6p90

URL: https://doi.org/10.5539/ijef.v12n6p90

\begin{abstract}
Based on two dimensions of system risk, this paper studies the changes in the future inflation risk level, and uses the out-of-sample quantile $R^{2}$ to further evaluate the predictive accuracy of different systemic risk indicators on inflation risk. Firstly, we compute two systemic risk indicators, MES and volatility, with data of Chinese financial institutions. And then we explore the amplification effect of these indicators on future inflation risk, under the framework of quantile regression. We find that systematic risk indicators have a strong predictive ability for the inflation level at various quantiles. MES indicator that reflects individual risk can better predict future deflation risk, while volatility index has a stronger ability to predict inflation risk. We also find that systemic risk indicators of different dimensions have different effects on inflation risk and deflation risk. In general, the MES index, which captures the individual risk of the organization, have a greater impact on the future inflation risk. While indicator that measures volatility in financial markets has more influence on the extreme lower tail of inflation rates. Finally, we predict the distribution of inflation in China from March 2020 to June 2021, and visually show the distribution trend of future inflation with forecast fan charts.
\end{abstract}

Keywords: financial market risk, inflation distribution, quantile regression model, out-of-sample R square

\section{Introduction}

As the economy continues to develop and productivity increase constantly, prices will inevitably rise. Continued price increases and excessive social aggregate demand will bring inflation. Moderate inflation can effectively promote stable economic growth. However, hyperinflation will seriously damage social welfare, and it will directly reduce the purchasing power of the currency and reduce consumption. Thus, it is very important to adopt appropriate fiscal and monetary policies in advance for the sake of preventing hyperinflation. The basis of achieving this goal is to find the underlying factors that may have impact on inflation rate. In recent years, with expanding financial activities, as well as innovating financial products, the relationship between financial market and the real economy is becoming closer and closer. Besides, with the continuous development of Chinese economy and the opening of financial markets, the relationship between Chinese financial market and international financial markets has become closer. Based on Johansen cointegration model, vector error correction model (VECM) and the generalized autoregressive conditional heteroskedastic model (GARCH), Guo shows that the US futures market has a significant spillover effect on the volatility of Chinese futures market (2017). Therefore, the possibility of fluctuation in Chinese financial market has further increased. What's worse, after the financial system is exposed to risks, it may further affects the real economy and have negative influence on inflation rate through credit channels. Therefore, how to prevent the negative spillover impact of financial risk on inflation risk and keep the bottom line where no systematic risk occurs is an important way to avoid hyperinflation.

After the global financial crisis in 2008, people came to realize that the financial market stress can not only cause losses to various institutions in the financial network, but also have a serious negative spillover effect on the real economy through credit channels. Thus, it is very important to timely measure and prevent systemic risk. Systemic risk can be divided into two dimensions: cross-section and time. From the cross-sectional perspective, there are direct or indirect connections between financial institutions within the financial system. When an institution falls into crisis, other institutions closely related to it will also be strongly impacted, resulting in liquidity tightening of the entire system. From the time dimension, risks will continue to accumulate within the system over time. Up to now, the measurement indicators of systemic risk can be divided into four categories, which are based on the perspective of institution-specific risk, volatility ang instability, comovement and 
contagion, as well as liquidity and credit (Giglio, Kelly, \& Pruitt, 2016). The conditional value-at-risk (CoVaR) index measures the contribution of individual institution to the overall risk of the financial market by calculating the difference between the values at risk of the financial system when the individual institution is in crisis and normal operation (Adrain \& Brunnermeier, 2016). The marginal expected loss (MES) index is also based on the perspective of individual institution risk, which captures the degree of contribution of individual financial institutions to financial market by calculating the conditional expected return of individual financial institutions When the return on assets of the entire financial system performs poorly (Acharya, Engle, \& Richardson, 2012). Illiquidity (AIM) indicator measures the liquidity and credit conditions in financial markets (Amihud, 2002).

When it comes to the mechanism by which financial system affects inflation rate, the relevant literature mostly believes that it is through credit channels, that is, when the financial system is in crisis, the supply of credit will shrink significantly, ending up with changes in price by affecting production costs. It has been proved that the $90^{\text {th }}$ percentile of the inflation distribution will significantly shift to the right, when there is real estate bubble and stock price bubble (Cecchetti \& Li, 2008). Research (Chen \& Wang, 2011) constructs the robustness index of Chinese banks and test the granger causality relationship between it and credit scale, as well as economic growth. The results show that this index has a two-way granger causality relationship with economic growth, and an one-way granger causality relationship with credit scale.

Since inflation rates that are too high or too low will limit the steady development of the economy, accurate predictions of future inflation risks are more conducive to the implementation of forward-looking policies than the forecast on the mean level. And it is of great academic value and practical significance to carry out in-depth research on the amplification effect and predictive ability of systemic risk, and to compare and analyze commonly used systemic risk indicators. It not only helps to further improve the system of measurement of systemic financial risks and clarify the spillover effect of financial risks on inflation, but also provides an important reference for theoretical analysis and empirical testing for the construction and improvement of China's inflation risk prevention system.

Based on two dimensions of system risk, this paper studies the changes in the future inflation risk level, and uses the out-of-sample quantile $R^{2}$ to evaluate the predictive accuracy of different systemic risk indicators on inflation risk. Firstly, we calculate two types of commonly used systemic risk indicators with data of Chinese financial institutions, which measure individual risk and financial sector volatility. And then we study the impact of these indicators on future inflation risk, including direction, intensity, and predictability. We find that system risk indicators can significantly improve the predictability of the model. Indicator that reflects individual risk can better predict future deflation risk, while volatility index has a stronger ability to predict inflation risk. In addition, systemic risk indicators based on different dimensions have significantly influence on inflation and deflation risk, while the results of OLS regression model show that such impact is not statistically significant. Specifically, as systemic risk rises, the risk of inflation or deflation will increase in the future, which is mainly reflected in the lag of 6 to 12 months. Indicator that measures individual risk has a greater impact on the extreme upper tail of inflation rates, while indicator that measures volatility in financial markets generally has an amplification effect on inflation rates at $70^{\text {th }}$ quantile and above. Finally, we predict the distribution of inflation in China from March 2020 to June 2021, and visually show the distribution trend of future inflation with forecast fan charts.

The remainder of the paper is organized in four sections. In Section 2, we analyze the mechanisms by which financial market risks affect inflation and deflation risk. In Section 3, we construct a quantile regression model and outline the calculation of systemic risk indicators. In Section 4, we evaluate predictive power of different systemic risk indicators to predict inflation risk, and examine the extent to which these risk indicators affect the inflation rate. In Section 5, we forecast future inflation risk in China. We conclude in Section 6.

\section{Mechanism of Spillover Effect of Financial Market Risk on Inflation}

\subsection{Systemic Risk and Inflation}

When there is a large profit space in the financial market, more and more investors will enter the market and make excessive investments. With undue expansion of investment demand, many non-performing loans will be created, causing a bubble in the financial market. In the process, systemic risk begins to accumulate. Once non-performing lenders find it difficult or impossible to meet their repayment obligations, such financial bubbles will burst. Due to the high uncertainty of future asset prices, as well as the negative expectations towards market outlook, investors and depositors tend to reduce investing activities and quickly withdraw funds, causing bank runs and widespread panic in the market. Eventually, liquidity tightened in the financial market. Because of the high correlation within the financial network, risks begin to spread among various institutions and even different 
departments, resulting in an accelerated rise in systemic risk. At this time, in order to avoid risks, some financial institutions will raise borrowing standards and reduce credit supply. The external financing of enterprises is difficult, and their own liquidity has declined. In this case, the company's investment is blocked, and it can only maintain its own survival by reducing the production scale, resulting in a reduction in the company's revenue. With the unchanged existing scale of the company's liabilities, its net assets decline, making the company have less access to credit. And this will make it more difficult to obtain loans from banks, which will form a vicious circle. The total production of the market will be greatly reduced, when more and more enterprises in the market are faced with similar difficulties, resulting in the total market supply unable to meet the total market demand. Thus, price will continue to rise. As a result, inflation follows.

\subsection{Systemic Risk and Deflation}

The reason why increasing systemic risk leads to deflation may depend on the demand side of credit activities. It has been proved that high borrowing costs and excessive leverage will cause the credit market to shrink Credit spreads widened (Ernst, Semmler, \& Haider, 2016). As mentioned above, when financial market continues to prosper, it is likely to produce excessive investment demand. Once this financial bubble is breached, the value of assets shrinks sharply, and public confidence in financial institutions declines. Based on pessimistic expectations of the future economy, funds will be withdrawn. Some banks will raise credit standards to reduce risks, making it more difficult for businesses and individuals to obtain loans. Because external financing is blocked, companies will reduce investment and production scale. At the same time, in order to cut back production costs, companies will also choose to lay off a large number of employees, resulting in a sharp rise in unemployment rate. Many people lose their sources of income and cannot obtain loans from banks, so their propensity to consume is weakened. On the other hand, in order to avoid greater losses, investors will retain funds and take a wait-and-see attitude. As a result, the investment and consumption demand of the entire market has shrunk dramatically. When this situation is gradually aggravated, it will cause the total market demand to be lower than the total market supply, causing prices to fall and inflation rate to fall. If this situation persists and cannot be alleviated, then deflation will be triggered.

\section{Model Construction and Data Analysis}

\subsection{Model Construction}

\subsubsection{Conditional Quantile Regression Model}

In order to study the impact of systemic risk on inflation rates at different quantiles, we construct a quantile regression model based on systemic risk indicators. The linear regression form of the model is as follows:

$$
\pi_{t}=\alpha+\beta \pi_{t-h}+\gamma S R_{t-h}+\varepsilon_{t}
$$

To capture the time varying dimension, we introduce a subscript $t$. In Equation (1), $\pi_{t-h}$ and $S R_{t-h}$ denotes the h-months lag of the inflation rate and the systemic risk indicator, respectively. $\varepsilon_{t}$ represents the error term. Therefore, the coefficient $\gamma$ measures the extent to which the h-months lag of systemic risk $S R_{t-h}$ influences inflation rate $\pi_{t}$. In order to capture the impact of financial market risk on the future inflation rate distribution, we use a quantile regression model.

$$
Q_{\pi_{t}}(\tau)=\alpha(\tau)+\beta(\tau) \pi_{t-h}+\gamma(\tau) S R_{t-h}
$$

where $\tau$ represents the quantile level, and its value range is $(0,1) . Q_{\pi_{t}}(\tau)$ denotes the $\tau^{\text {th }}$ quantile of the inflation distribution conditional on lagged inflation rate $\pi_{t-h}$ and systemic risk indicator $S R_{t-h}$. Thus, by setting different $\tau$ values, we can study the degree to which systemic risk indicators have influence on inflation rate at various quantiles.

In order to get the estimators of coefficients $\alpha(\tau), \beta(\tau)$ and $\gamma(\tau)$, make sure that the sum of the weighted absolute values of the error terms is minimized:

$$
\hat{\eta}(\tau)=\operatorname{argmin}_{\eta_{\tau} \in \mathrm{R}^{\mathrm{k}}} \sum_{\mathrm{t}=1}^{\mathrm{T}-\mathrm{h}}\left(\tau * \mathrm{I}_{\left(\pi_{\mathrm{t}} \geq \mathrm{X}_{\mathrm{t}-\mathrm{h}}\right)}\left|\pi_{\mathrm{t}}-\mathrm{X}_{\mathrm{t}-\mathrm{h}}\right|+(1-\tau) * \mathrm{I}_{\left(\pi_{\mathrm{t}}<\mathrm{X}_{\mathrm{t}-\mathrm{h}}\right)}\left|\pi_{\mathrm{t}}-\mathrm{X}_{\mathrm{t}-\mathrm{h}}\right|\right)
$$

where $X_{t-h}=\alpha(\tau)+\beta(\tau) \pi_{t}+\gamma(\tau) S R_{t-h}, \hat{\eta}(\tau)=\{\hat{\alpha}(\tau), \hat{\beta}(\tau), \hat{\gamma}(\tau)\}$. I(') is the indicator function. If the condition in $(\cdot)$ is satisfied, then $I_{(\cdot)}$ equals to 1 , otherwise, it equals to 0 . With the estimators $\hat{\eta}(\tau)$, we can get the fitted values:

$$
\hat{Q}_{\pi_{t}}(\tau)=\hat{\alpha}(\tau)+\hat{\beta}(\tau) \pi_{t-h}+\hat{\gamma}(\tau) S R_{t-h}
$$




\subsubsection{Implication of the Coefficients}

The key coefficient we are interested in is $\hat{\gamma}(\tau)$, which quantifies the degree to which inflation rate changes at $\tau^{\text {th }}$ percentile when the overall risk level of the financial market rises by 1 unit. The systemic risk indexes selected are MES (Marginal Expected Shortfall) and Volatility. In terms of MES, lower indicator level symbolizes higher financial market risk. Thus, when $\tau=0.1$, if $\hat{\gamma}(\tau)>0$, it indicates that when MES declines, which means that system risk increases, the future inflation rate at $10 \%$ quantile will shift to the left, which means that the deflation risk will be driven up. When $\tau=0.9$, if $\hat{\gamma}(\tau)<0$, it implies that with decreasing index level, the future inflation rate on $90 \%$ quantile will shift to the right, indicating the possibility of future inflation will go up. Therefore, based on different symbols and numerical sizes of $\hat{\gamma}(\tau)$, we can explore the impact of different systemic risk indicators on future inflation and deflation risk.

\subsubsection{Out-of-Sample $R^{2}$}

Following Giglio et al. (2016), we compute the out-of-sample quantile $R^{2}$ to evaluate the forecast accuracy of the quantile regression model conditional on systemic risk indicators. The expression is constructed as follows:

$$
R^{2}=1-\frac{\frac{1}{\bar{T}} \sum_{t-h}\left[\rho_{\tau}\left(\pi_{t}-\widehat{\alpha}(\tau)-\widehat{\beta}(\tau) \pi_{t-h}-\widehat{\gamma}(\tau) S R_{t-h}\right)\right]}{\frac{1}{T} \sum_{t-h}\left[\rho_{\tau}\left(\pi_{t}-\hat{q}_{\pi}(\tau)\right)\right]}
$$

$\rho_{\tau}(\cdot)$ denotes a weighted loss function. And $\hat{q}_{\pi}(\tau)$ denotes the estimate based on the historical unconditional quantile regression, that is, the explanatory variables of this model do not include indicators which measure financial market risk. The numerator in Equation (5) indicates the loss sequence of conditional model based on systemic risk indicators, and the denominator indicates the loss sequence of unconditional model which do not take the impact of financial risk into consideration. From this, if the value of $R^{2}$ is greater than zero, we can say that the predictive power of the quantile regression conditional on systemic risk index is better than the model which doesn't consider the impact of financial market risk. However, if the value of $R^{2}$ is negative, the forecast power of the quantile regression conditional on systemic risk index is relatively poorer, compared to the unconditional model. Therefore, positive and larger value of the out-of-sample $R^{2}$ indicates the stronger forecast accuracy of the conditional quantile regression model which take systemic risk index into account, compared to the unconditional model which neglects the lagging terms of indicators measuring overall financial market risk.

\subsection{Data Analysis}

\subsubsection{Systemic Risk}

According to Giglio et al. (2016), the indicators to measure systemic risk can be divided into four levels, including the perspectives based on institution-specific risk, volatility and instability, linkage and contagion, as well as comovement and credit. The MES index selected in this paper is systemic risk indicator measuring individual institutional risks, while Volatility indicator is based on the volatility of individual institutions.

Our sample includes publicly traded financial institutions in both Shenzhen Component and Shanghai Composite, covering all financial sectors in the financial market, including commercial banks, security broker-dealers, insurance companies, real estate companies and all other sectors which are placed in an "other" category. We have a total of 236 financial institutions in our sample. And we start our sample in January 1991 to August 2019. We collect data from the RESSET Database, including daily closing price and market value of individual financial institutions.

\section{(a) Institution-Specific Risk}

On the basis of expected losses (ES), Acharya et al. (2012) proposed marginal expected losses (MES), which measures the marginal contribution of individual financial institutions to the overall financial risk in the event of a systemic crisis in the financial market. The expected loss (ES) of individual financial institutions refers to the expected value of the return rate of institution $j$, when the return rate $R^{j}$ is lower than $V a R^{j}$ in a certain period of time.

$$
E S^{j}=-E\left[R^{j} \mid R^{j} \leq V a R^{j}\right]
$$

where $V a R^{j}$ denotes the value at risk of the institution $j$.

However, MES measures the conditional expected rate of return of institution $j$ 's financial assets return when the return on assets of overall financial system is at the bottom ( $2 \%$ of the worst time).

$$
M E S^{j}=E\left[R^{j} \mid R^{\text {system }}<q\right]
$$

In order to obtain the time-varying MES of individual financial institutions, we use the Binary Conditional 
Heteroscedastic Model (DCC-GARCH) proposed by Brownlees and Engle (2011) to characterize the dynamic changes in the returns of institution $j$ and the overall financial market.

$$
M E S_{t}^{j}=\sigma_{j, t} \rho_{j, t} E\left[\epsilon_{\text {system }, t} \mid \epsilon_{\text {system }, t}<\frac{K}{\sigma_{\text {system }, t}}\right]+\sigma_{j, t} \sqrt{1-\rho_{j, t}^{2}} E\left[\epsilon_{j, t} \mid \epsilon_{\text {system }, t}<\frac{K}{\sigma_{\text {system }, t}}\right]
$$

where $\epsilon_{j, t}$ and $\epsilon_{s y s t e m, t}$ are the residual of the volatility of institution $j$ 's return and market returns, respectively. Both $\epsilon_{j, t}$ and $\epsilon_{\text {system, }}$ follow the standard normal distribution, but they are not independent of each other. Besides, $\sigma_{j, t}$ and $\sigma_{s y s t e m, t}$ are the standard deviation of institution $j$ 's return and market returns, respectively. And $\rho_{j, t}$ is the correlation between institution $j$ 's return and markets return. These parameters are obtained by GARCH/DCC model. $K$ is set to 2, following Brownlees and Engle (2011).

(b) Volatility

To capture the impact of financial sector volatility, we compute the Volatility index, which is based on the daily data of individual financial institution's rate of return, according to its market value. And it is weighted average of monthly standard deviation of rate of return, which measures the average level of volatility in the financial market.

\subsubsection{Inflation Rate}

The indicators for measuring inflation rate generally focus on the consumer price index (CPI), producer price index (PPI), and GDP deflator. This paper uses the year-on-year change in the CPI index to calculate the inflation level in China. From the perspective of resident consumption, CPI reflects the changes in the price of consumer goods and service items generally purchased by resident households. The changes in the index reflect the degree of inflation or deflation to a certain extent. Generally speaking, an overall and sustained increase in price is considered that inflation emerges. In order to capture the underlying trend of inflation rate, we make seasonal adjustment. The data of consumer price index come from the Federal Reserve Economic Database (FRED) as well as the RESSET Database. We define inflation rate as follows:

$$
\pi_{t}=\ln \left(\frac{P_{t}}{P_{t-12}}\right)
$$

where $P_{t}$ denotes the current CPI index, while $P_{t-12}$ represents 12-months-lagged price index.

\subsection{Statistics}

Table 1 reports summary statistics for inflation rate, marginal expected shortfall (MES) and volatility during the sample period. It can be seen that the skewness of both inflation and volatility are positive, so the distribution of inflation rate and volatility index is right-biased. And these three variables all have a large kurtosis value, indicating that there is a "fat tail" of inflation and systemic risk indicators during the sample period Features. The kurtosis of the two systemic financial risk indicators is relatively large, indicating that the probability of extreme values appearing in financial market risk is high. Besides, the skewness of MES is negative, suggesting that during the sample period, there is a period of extremely high level of systemic risk.

Table 1. Summary statistics

\begin{tabular}{cccccccc}
\hline Variable & Observations & Min & Max & Mean & Std. Dev. & Skewness & Kurtosis \\
\hline Inflation & 344 & -2.616 & 27.665 & 4.113 & 5.770 & 2.205 & 7.798 \\
MES & 344 & -0.163 & -0.034 & -0.060 & 0.019 & -1.750 & 7.765 \\
Volatility & 344 & 0.011 & 0.138 & 0.030 & 0.014 & 2.710 & 16.550 \\
\hline
\end{tabular}

We also compute the correlation between different systemic financial risk indicators, as shown in Table 2. It can be seen that the correlation between the two types of indicators is low, indicating that different measurement indicators reflect systemic risk from different aspects. Therefore, the research on the relationship between systemic risk indicators and inflation risk can help us identify more appropriate systemic financial risk indicators.

Table 2. Correlation between different systemic risk indicators.

\begin{tabular}{ccc}
\hline Variable & MES & Volatility \\
\hline MES & 1 & \\
Volatility & -0.874 & 1 \\
\hline
\end{tabular}




\section{Results}

\subsection{Forecast Accuracy}

\subsubsection{Institution-Specific Risk}

Table 3 and Table 4 report the out-of-sample quantile $R^{2}$ of model (2). And these tables report the ability of the MES indicator in different lags to predict the inflation level at the low and high quantiles, respectively. Comparing Table 3 and Table 4, it can be seen that systemic risk index MES has a stronger forecast accuracy for the inflation rate at lower quantile. In addition, as the lag period extends to 9 months or 12 months, the out-of-sample quantile $R^{2}$ increases, indicating that the MES indicator has a better prediction effect on CPI inflation in the long run. Furthermore, when the out-of-sample start time is 2016 or 2017, the out-of-sample quantile $R^{2}$ is generally larger, and the prediction ability is relatively stronger at this time.

Table 3a. Out-of-Sample Forecast Accuracy (MES) for lower quantile: $\tau=0.1$

\begin{tabular}{cccccc}
\hline & $\mathrm{h}=1$ & $\mathrm{~h}=3$ & $\mathrm{~h}=6$ & $\mathrm{~h}=9$ & $\mathrm{~h}=12$ \\
\cline { 2 - 6 } Out of sample starting time & MES & MES & MES & MES & MES \\
\hline 2012 & 0.25 & 0.24 & 2.58 & 1.46 & 4.53 \\
2013 & 0.32 & 0.11 & 2.44 & 5.11 & 3.76 \\
2014 & 0.44 & 0.16 & 1.88 & 1.82 & 3.30 \\
2015 & 0.10 & 0.18 & 0.67 & 2.70 & 11.32 \\
2016 & 10.67 & 13.97 & 0.02 & 1.20 & 27.63 \\
2017 & 9.58 & 0.66 & 16.33 & 3.76 & 0.13 \\
\hline
\end{tabular}

Note. The table reports out-of-sample quantile $R^{2}$ (in percentage) relative to the historical quantile model. $\mathrm{h}=1,3,6,9$ and 12 represent lags of 1 month, 3, 6, 9 and 12 months, respectively. For the inflation rate, 10-\% quantile regressions are run on the lagged systemic risk index MES.

Table 3b. Out-of-Sample Forecast Accuracy (MES) for lower quantile: $\tau=0.2$.

\begin{tabular}{cccccc}
\hline & $\mathrm{h}=1$ & $\mathrm{~h}=3$ & $\mathrm{~h}=6$ & $\mathrm{~h}=9$ & $\mathrm{~h}=12$ \\
\cline { 2 - 6 } Out of sample starting time & MES & MES & MES & MES & MES \\
\hline 2012 & 0.35 & 0.46 & 1.53 & 3.95 & 0.29 \\
2013 & 0.75 & 0.31 & 2.87 & 6.23 & 2.65 \\
2014 & 0.49 & 0.03 & 1.90 & 4.80 & 1.90 \\
2015 & 0.75 & 0.05 & 1.35 & 6.34 & 5.11 \\
2016 & 8.01 & 9.96 & 0.33 & 4.91 & 25.68 \\
2017 & 5.26 & 0.81 & 16.65 & 4.17 & 1.99 \\
\hline
\end{tabular}

Note. The table reports out-of-sample quantile $R^{2}$ (in percentage) relative to the historical quantile model. $\mathrm{h}=1,3,6,9$ and 12 represent lags of 1 month, 3, 6, 9 and 12 months, respectively. For the inflation rate, 20-\% quantile regressions are run on the lagged systemic risk index MES.

Table 4a. Out-of-Sample Forecast Accuracy (MES) for higher quantile: $\tau=0.8$

\begin{tabular}{cccccc}
\hline & $\mathrm{h}=1$ & $\mathrm{~h}=3$ & $\mathrm{~h}=6$ & $\mathrm{~h}=9$ & $\mathrm{~h}=12$ \\
\cline { 2 - 6 } Out of sample starting time & MES & MES & MES & MES & MES \\
\hline 2012 & 0.39 & 0.12 & 0.77 & 0.02 & 4.47 \\
2013 & 0.40 & 0.00 & 0.21 & 0.94 & 3.48 \\
2014 & 0.47 & 0.24 & 1.68 & 0.88 & 4.92 \\
2015 & 0.58 & 0.60 & 0.35 & 0.69 & 5.66 \\
2016 & 3.11 & 3.80 & 1.47 & 0.56 & 0.09 \\
2017 & 3.59 & 16.35 & 21.56 & 1.72 & 4.69 \\
\hline
\end{tabular}

Note. The table reports out-of-sample quantile $R^{2}$ (in percentage) relative to the historical quantile model. $\mathrm{h}=1,3,6,9$ and 12 represent lags of 1 month, 3, 6, 9 and 12 months, respectively. For the inflation rate, 80-\% quantile regressions are run on the lagged systemic risk index MES. 
Table 4b. Out-of-Sample Forecast Accuracy (MES) for higher quantile: $\tau=0.9$

\begin{tabular}{cccccc}
\hline & $\mathrm{h}=1$ & $\mathrm{~h}=3$ & $\mathrm{~h}=6$ & $\mathrm{~h}=9$ & $\mathrm{~h}=12$ \\
\cline { 2 - 6 } Out of sample starting time & MES & MES & MES & MES & MES \\
\hline 2012 & 0.44 & 1.35 & 1.74 & 1.22 & 5.42 \\
2013 & 0.03 & 1.61 & 2.68 & 0.41 & 3.95 \\
2014 & 0.02 & 2.01 & 1.84 & 0.27 & 4.45 \\
2015 & 0.08 & 2.83 & 3.61 & 1.19 & 10.69 \\
2016 & 0.20 & 4.78 & 1.61 & 0.02 & 2.66 \\
2017 & 6.45 & 15.00 & 4.12 & 1.18 & 0.66 \\
\hline
\end{tabular}

Note. The table reports out-of-sample quantile $R^{2}$ (in percentage) relative to the historical quantile model. $\mathrm{h}=1,3,6,9$ and 12 represent lags of 1 month, 3, 6, 9 and 12 months, respectively. For the inflation rate, 90-\% quantile regressions are run on the lagged systemic risk index MES.

\subsubsection{Volatility}

Table 5 and Table 6 show out-of-sample quantile $R^{2}$ based on volatility indicators. Consistent with previous results, as the lag period extends, the out-of-sample $R^{2}$ gradually increases. In terms of lower quantile, the $R^{2}$ reaches its maximum when lagging by 9 to 12 months, implying stronger predictive power. When it comes to upper quantile, lagging 12 months is optimal. In addition, the $R^{2}$ at lower quantile is generally greater, compared with $R^{2}$ at upper quantile, which indicates that volatility index has a stronger predictive power for deflation risk. Besides, compared with MES index, the out-of-sample quantile $R^{2}$ based on volatility is larger at upper quantile, indicating that volatility index has stronger predictive power for the risk of inflation than institution-specific risks.

Table 5a. Out-of-Sample Forecast Accuracy (Volatility) for lower quantile: $\tau=0.1$

\begin{tabular}{cccccc}
\hline & $\mathrm{h}=1$ & $\mathrm{~h}=3$ & $\mathrm{~h}=6$ & $\mathrm{~h}=9$ & $\mathrm{~h}=12$ \\
\cline { 2 - 5 } Out of sample starting time & volatility & volatility & volatility & volatility & volatility \\
\hline 2012 & 0.00 & 0.20 & 2.19 & 2.40 & 2.52 \\
2013 & 0.06 & 0.12 & 2.53 & 6.92 & 3.58 \\
2014 & 0.20 & 0.18 & 1.46 & 4.54 & 4.92 \\
2015 & 0.28 & 0.18 & 0.44 & 4.02 & 8.79 \\
2016 & 8.28 & 7.79 & 0.01 & 2.14 & 20.76 \\
2017 & 8.48 & 0.06 & 16.88 & 5.38 & 5.99 \\
\hline
\end{tabular}

Note. The table reports out-of-sample quantile $R^{2}$ (in percentage) relative to the historical quantile model. $\mathrm{h}=1,3,6,9$ and 12 represent lags of 1 month, 3, 6, 9 and 12 months, respectively. For the inflation rate, 10-\% quantile regressions are run on the lagged systemic risk index volatility.

Table 5b. Out-of-Sample Forecast Accuracy (Volatility) for lower quantile: $\tau=0.2$.

\begin{tabular}{cccccc}
\hline & $\mathrm{h}=1$ & $\mathrm{~h}=3$ & $\mathrm{~h}=6$ & $\mathrm{~h}=9$ & $\mathrm{~h}=12$ \\
\cline { 2 - 6 } Out of sample starting time & volatility & volatility & volatility & volatility & volatility \\
\hline 2012 & 0.29 & 0.70 & 0.57 & 4.37 & 0.16 \\
2013 & 0.74 & 0.66 & 2.17 & 6.38 & 2.30 \\
2014 & 0.45 & 0.12 & 0.30 & 5.57 & 1.90 \\
2015 & 0.24 & 0.06 & 0.61 & 7.11 & 3.91 \\
2016 & 8.64 & 5.99 & 0.60 & 4.74 & 19.12 \\
2017 & 7.32 & 0.17 & 12.38 & 5.60 & 11.46 \\
\hline
\end{tabular}

Note. The table reports out-of-sample quantile $R^{2}$ (in percentage) relative to the historical quantile model. $\mathrm{h}=1,3,6,9$ and 12 represent lags of 1 month, 3, 6, 9 and 12 months, respectively. For the inflation rate, 20-\% quantile regressions are run on the lagged systemic risk index volatility. 
Table 6a. Out-of-Sample Forecast Accuracy (Volatility) for higher quantile: $\tau=0.8$

\begin{tabular}{cccccc}
\hline Out of sample starting time & $\begin{array}{c}\mathrm{h}=1 \\
\text { volatility }\end{array}$ & $\begin{array}{c}\mathrm{h}=3 \\
\text { volatility }\end{array}$ & $\begin{array}{c}\mathrm{h}=6 \\
\text { volatility }\end{array}$ & $\begin{array}{c}\mathrm{h}=9 \\
\text { volatility }\end{array}$ & $\begin{array}{c}\mathrm{h}=12 \\
\text { volatility }\end{array}$ \\
\hline 2012 & 0.51 & 0.02 & 1.14 & 0.04 & 4.14 \\
2013 & 0.60 & 0.01 & 0.35 & 1.58 & 3.40 \\
2014 & 0.77 & 0.31 & 0.63 & 1.43 & 5.44 \\
2015 & 1.01 & 0.34 & 0.82 & 1.20 & 5.39 \\
2016 & 4.21 & 5.10 & 0.79 & 0.19 & 0.08 \\
2017 & 8.45 & 14.50 & 8.83 & 2.49 & 0.58 \\
\hline
\end{tabular}

Note. The table reports out-of-sample quantile $R^{2}$ (in percentage) relative to the historical quantile model. $\mathrm{h}=1,3,6,9$ and 12 represent lags of 1 month, 3, 6, 9 and 12 months, respectively. For the inflation rate, 80-\% quantile regressions are run on the lagged systemic risk index volatility.

Table 6b. Out-of-Sample Forecast Accuracy (Volatility) for higher quantile: $\tau=0.9$

\begin{tabular}{cccccc}
\hline & $\mathrm{h}=1$ & $\mathrm{~h}=3$ & $\mathrm{~h}=6$ & $\mathrm{~h}=9$ & $\mathrm{~h}=12$ \\
\cline { 2 - 6 } Out of sample starting time & volatility & volatility & volatility & volatility & volatility \\
\hline 2012 & 0.10 & 0.30 & 1.72 & 1.38 & 4.53 \\
2013 & 0.09 & 1.21 & 3.81 & 0.09 & 4.14 \\
2014 & 0.50 & 1.10 & 2.52 & 0.08 & 4.12 \\
2015 & 0.98 & 1.88 & 5.13 & 0.27 & 8.21 \\
2016 & 7.73 & 7.05 & 0.15 & 0.81 & 2.20 \\
2017 & 15.79 & 13.59 & 1.28 & 2.09 & 0.94 \\
\hline
\end{tabular}

Note. The table reports out-of-sample quantile $R^{2}$ (in percentage) relative to the historical quantile model. $\mathrm{h}=1,3,6,9$ and 12 represent lags of 1 month, 3, 6, 9 and 12 months, respectively. For the inflation rate, 80-\% quantile regressions are run on the lagged systemic risk index volatility.

\subsection{Significance Test}

\subsubsection{Institution-Specific Risk}

We obtain the spillover effects of overall financial market risk towards inflation risk by running quantile regressions of inflation rate on the lagged systemic risk indicators. We report significance test of both quantile and OLS regression model under various lag time in Table 7. Among them, MES index has been standardized.

OLS regression results are generally negative, but not statistically significant, which is different from the quantile regression results. Thus, point estimation using OLS regression is very possible to ignore the spillover effects of financial markets on inflation risk, ending up with failure to effectively prevent and control inflation risk

In addition, at lower quantiles, the coefficient $\gamma(\tau)$ of MES is positive, indicating that when this index falls, that is, systemic risk rises, the lower percentiles of the inflation distribution will shift to the left, indicating that deflation risk may go up. However, in terms of upper percentile, $\gamma(\tau)$ becomes negative, which suggests that when systemic risk increases, the high percentile of the inflation distribution will shift to the right, that is, the risk of inflation rises. For example, the coefficient of -1.214 for the MES forecast at the 12-month horizon implies that when MES reduces by 1 standard deviation, the value on the $90^{\text {th }}$ percentile of inflation distribution will shift significantly to the right by $1.214 \%$, which means that the risk of inflation in the future will increase.

Besides, with the extension of the lag period, the absolute value of the coefficient gradually increases, and statistical significance appears after 6 months of lag, indicating that in the short term, systemic risk caused by individual institutional risks will not amplify inflation risk. However, this amplification effect will gradually appear over time. Apart from this, under the same conditions, the estimated value of the coefficients $\gamma(\tau)$ at high quantiles (in absolute value) is greater than the those at low quantiles, which shows that compared with deflation risk, the impact of rising financial market risk on inflation risk is bigger. 
Table 7. t-Statistics of Systemic Indicators Exposures - MES

\begin{tabular}{cccccc}
\hline \multirow{2}{*}{ Quantiles } & $\mathrm{h}=1$ & $\mathrm{~h}=3$ & $\mathrm{~h}=6$ & $\mathrm{~h}=9$ & $\mathrm{~h}=12$ \\
\cline { 2 - 5 }$\tau=0.1$ & $\mathrm{MES}$ & $\mathrm{MES}$ & $\mathrm{MES}$ & $\mathrm{MES}$ & $\mathrm{MES}$ \\
\hline \multirow{2}{*}{$\tau=0.3$} & 0.101 & $0.391 * *$ & $0.902 * * *$ & $0.968^{* * *}$ & $0.944 * * *$ \\
& $(0.10)$ & $(0.18)$ & $(0.26)$ & $(0.31)$ & $(0.33)$ \\
$\tau=0.5$ & 0.026 & -0.046 & -0.002 & -0.014 & 0.166 \\
& $(0.05)$ & $(0.15)$ & $(0.23)$ & $(0.36)$ & $(0.29)$ \\
$\tau=0.7$ & -0.021 & -0.112 & -0.153 & -0.144 & -0.166 \\
& $(0.05)$ & $(0.13)$ & $(0.12)$ & $(0.19)$ & $(0.21)$ \\
$\tau=0.9$ & -0.038 & -0.117 & $-0.406 * *$ & $-0.887 * * *$ & $-0.930^{* *}$ \\
& $(0.05)$ & $(0.08)$ & $(0.17)$ & $(0.29)$ & $(0.42)$ \\
$\tau=0.95$ & -0.049 & -0.064 & $-0.735 * * *$ & $-1.012 * * *$ & $-1.214 * * *$ \\
& $(0.08)$ & $(0.19)$ & $(0.25)$ & $(0.27)$ & $(0.42)$ \\
OLS & 0.091 & -0.166 & $-0.500 * *$ & $-0.740 * * *$ & $-0.864 * *$ \\
& $(0.13)$ & $(0.18)$ & $(0.25)$ & $(0.24)$ & $(0.34)$ \\
\end{tabular}

Note. Parentheses show the standard error of $\gamma(\tau)$. Statistical significance at the $10 \%, 5 \%$ and $1 \%$ levels are denoted by $*$, $* *$ and $* * *$, respectively.

\subsubsection{Volatility}

Unlike MES index, the larger the volatility indicator, the greater change in the financial institution's rate of return as well as the higher risk of the financial system. Thus, positive $\gamma(\tau)$ represents that rising systemic risk will lead to an increase in the specific quantile of the inflation distribution.

Table 8 reports the significance test based on the quantile regression and OLS regression estimation coefficients of the volatility index, which has been standardized. It can be seen from the table that when the lag period is extended from 9 months to 12 months, the coefficient of volatility is significantly positive at the high quantile, which indicates that when volatility increases, that is, the risk of financial system rises, higher percentile of the inflation distribution will shift significantly to the right, and the probability that the inflation rate is higher than a certain value becomes greater, so the risk of inflation in the future increases. Secondly, when $\tau=0.1$, the coefficient is significantly negative, which is consistent with the previous results. For instance, the coefficient of -1.015 for the volatility forecast at the 12 -month horizon implies that when financial sector volatility increases by 1 standard deviation, the value on the $10^{\text {th }}$ percentile of inflation distribution will shift significantly to the left by $1.015 \%$, which means that the risk of deflation in the future will increase.

However, unlike MES, the OLS regression result based on volatility index is significantly positive, indicating that financial system volatility has a significant positive effect on the average level of inflation.

Table 8. t-Statistics of Systemic Indicators Exposures - Volatility

\begin{tabular}{cccccc}
\hline \multirow{2}{*}{ Quantiles } & $\mathrm{h}=1$ & $\mathrm{~h}=3$ & $\mathrm{~h}=6$ & $\mathrm{~h}=9$ & $\mathrm{~h}=12$ \\
\cline { 2 - 6 }$\tau=0.1$ & volatility & volatility & volatility & volatility & volatility \\
\hline \multirow{2}{*}{$\tau=0.3$} & -0.028 & $-0.341^{*}$ & -0.586 & $-0.908^{* * *}$ & $-1.015^{* * *}$ \\
& $(0.10)$ & $(0.21)$ & $(0.38)$ & $(0.35)$ & $(0.35)$ \\
$\tau=0.5$ & -0.005 & 0.086 & 0.124 & 0.158 & -0.091 \\
& $(0.04)$ & $(0.11)$ & $(0.24)$ & $(0.38)$ & $(0.36)$ \\
$\tau=0.7$ & 0.046 & 0.146 & 0.18 & $0.360^{* *}$ & 0.273 \\
& $(0.05)$ & $(0.11)$ & $(0.15)$ & $(0.18)$ & $(0.32)$ \\
$\tau=0.9$ & 0.074 & 0.16 & $0.429^{* *}$ & $0.608^{*}$ & $0.970^{* * *}$ \\
& $(0.05)$ & $(0.12)$ & $(0.18)$ & $(0.36)$ & $(0.36)$ \\
$\tau=0.95$ & 0.135 & 0.034 & $0.697^{* *}$ & $0.831^{* * *}$ & $0.727^{*}$ \\
& $(0.11)$ & $(0.18)$ & $(0.32)$ & $(0.30)$ & $(0.39)$ \\
OLS & 0.149 & 0.108 & 0.471 & $0.724^{* * *}$ & $0.768^{*}$ \\
& $(0.17)$ & $(0.18)$ & $(0.33)$ & $(0.26)$ & $(0.39)$ \\
& 0.069 & 0.094 & 0.228 & $0.375^{*}$ & $0.476^{*}$ \\
& $(0.04)$ & $(0.09)$ & $(0.15)$ & $(0.20)$ & $(0.24)$ \\
\hline
\end{tabular}

Note. Parentheses show the standard error of $\gamma(\tau)$. Statistical significance at the $10 \%, 5 \%$ and $1 \%$ levels are denoted by $*$, ** and $* * *$, respectively.

According to Table 7 and Table 8, it can be concluded that increasing financial market risk will lead to rising inflation risk and deflation risk. In addition, comparing the results of these two tables, we can find that as far as 
lower quantile, the absolute value of the coefficient of volatility index is greater than that of MES. In terms of higher quantile, the absolute value of the coefficients of MES are relatively larger. Therefore, the financial market pressure caused by the risk of individual institutions has a greater impact on the future inflation risk. And systemic risk based on fluctuations in the financial sector is more likely to cause deflation risk to rise.

\subsection{Robustness Test}

In order to ensure the robustness of the empirical results, we replace the indicator that measures Chinese inflation rate, that is, the inflation rate is calculated using the year-on-year change in producer price index (PPI). The data comes from the Federal Reserve Economic Database (FRED) and is seasonally adjusted. Due to the constraint of available data, the sample interval is from January 1999 to August 2019.

Table 9 is about the out-of-sample quantile $R^{2}$ at $90^{\text {th }}$ percentile based on volatility index. The measurement of inflation rate is PPI. See Appendix A for the out-of-sample predictive accuracy on other percentiles. It can be found from the comprehensive results that with the extension of the lag period, the out-of-sample prediction effect gradually increases. When the lag period is 6 months or 9 months, the out-of-sample quantile $R^{2}$ reaches a maximum. At the same time, it is also noted that the predictive power for higher quantile is generally stronger than that for lower quantile.

Table 10 shows the significance test of the quantile regression and OLS regression estimation coefficients based on volatility index, which have been standardized, and the inflation of the explained variables is determined by the producer price index (PPI). This result is consistent with the empirical results, that is, the coefficient is significantly negative at higher quantile and positive at lower quantile, indicating that the overall risk of rising financial market will amplify future inflation risk as well as deflation risk.

Table 9. Out-of-Sample $90^{\text {th }}$ Percentile PPI Inflation Forecasts

\begin{tabular}{cccccc}
\hline & $\mathrm{h}=1$ & $\mathrm{~h}=3$ & $\mathrm{~h}=6$ & $\mathrm{~h}=9$ & $\mathrm{~h}=12$ \\
Out of sample starting time & volatility & volatility & volatility & volatility & \begin{tabular}{c} 
volatility \\
\hline 2012
\end{tabular} \\
2013 & 6.950 & 3.694 & 9.627 & 7.816 & 0.160 \\
2014 & 6.469 & 6.203 & 15.021 & 10.799 & 0.039 \\
2015 & 7.281 & 10.110 & 20.955 & 14.905 & 1.860 \\
2016 & 9.749 & 20.212 & 29.064 & 24.716 & 5.644 \\
2017 & 8.182 & 24.492 & 17.441 & 12.975 & 7.501 \\
\hline
\end{tabular}

Note. The table reports out-of-sample quantile $R^{2}$ (in percentage) relative to the historical quantile model. $\mathrm{h}=1,3,6,9$ and 12 represent lags of 1 month, 3, 6, 9 and 12 months, respectively. For the inflation rate, 80-\% quantile regressions are run on the lagged systemic risk index volatility.

Table 10. t-Statistics of Systemic Indicators Exposures - PPI Inflation

\begin{tabular}{cccccc}
\hline \multirow{2}{*}{ Quantiles } & $\mathrm{h}=1$ & $\mathrm{~h}=3$ & $\mathrm{~h}=6$ & $\mathrm{~h}=9$ & $\mathrm{~h}=12$ \\
\cline { 2 - 6 }$\tau=0.1$ & volatility & volatility & volatility & volatility & volatility \\
\hline \multirow{2}{*}{$\tau=0.3$} & $-0.521^{*}$ & -1.128 & -1.772 & $-2.331^{* *}$ & $-1.441^{*}$ \\
& $(0.31)$ & $(0.72)$ & $(1.17)$ & $(0.92)$ & $(0.76)$ \\
$\tau=0.5$ & -0.048 & -0.017 & 0.066 & 0.002 & 0.065 \\
& $(0.11)$ & $(0.36)$ & $(0.61)$ & $(0.86)$ & $(0.95)$ \\
$\tau=0.7$ & 0.021 & -0.073 & 0.175 & 0.058 & 0.181 \\
& $(0.08)$ & $(0.25)$ & $(0.42)$ & $(0.60)$ & $(0.66)$ \\
$\tau=0.9$ & -0.115 & 0.01 & -0.212 & 0.594 & 1.234 \\
& $(0.11)$ & $(0.21)$ & $(0.53)$ & $(0.65)$ & $(0.90)$ \\
$\tau=0.95$ & 0.075 & -0.024 & $1.049^{*}$ & $1.080^{* * *}$ & $1.001^{* *}$ \\
& $(0.14)$ & $(0.35)$ & $(0.62)$ & $(0.42)$ & $(0.50)$ \\
OLS & -0.128 & 0.353 & $1.174 * *$ & $1.492^{* * *}$ & 0.755 \\
& $(0.21)$ & $(0.54)$ & $(0.55)$ & $(0.52)$ & $(0.48)$ \\
& $-0.139^{*}$ & $-0.357^{*}$ & -0.511 & -0.398 & -0.064 \\
& $(0.08)$ & $(0.21)$ & $(0.33)$ & $(0.38)$ & $(0.40)$ \\
\hline
\end{tabular}

Note. Parentheses show the standard error of $\gamma(\tau)$. Statistical significance at the $10 \%, 5 \%$ and $1 \%$ levels are denoted by $*$, ** and ***, respectively. The systemic risk measurement index is volatility index reflecting the fluctuation of financial sectors. The inflation rate is calculated from the year-on-year change in PPI. 


\section{Inflation Risk Forecasting}

We use the systemic risk indicator volatility, which measures the fluctuations of financial sector, to predict Chinese inflation risk from March 2020 to June 2021. The predicted values of the inflation rate distribution are shown in Appendix B.

In order to visually show the trend of China's inflation risk in the coming year, we draw a fan chart of inflation forecast, following the inflation forecast reports of the Bank of England. Forecast fan charts are usually used to show the confidence interval of the prediction results and the results of risk prediction. It is a set of time series images around the average or median, and the shaded area in the figure represents the probability. This image can intuitively show the future distribution of the series. Figure 1 shows the Chinese inflation forecasting fan charts. The shaded bands of different colors in Figure 1 represent the possibility of different degrees. The darkest shaded band indicates that the probability of future inflation falling into this area is $40 \%$, and the lightest color indicates that this probability is $90 \%$. Thus, there is a $90 \%$ possibility that future inflation will fall into the overall shadow range shown in the graph, and only $10 \%$ may exceed the shadow range. larger area of the shaded area means greater probability. As can be seen from Figure 1, compared to the shaded area below the median line, the shaded area above the median line is larger, which implies that the possibility of inflation in the future is rising, based on financial market distress.

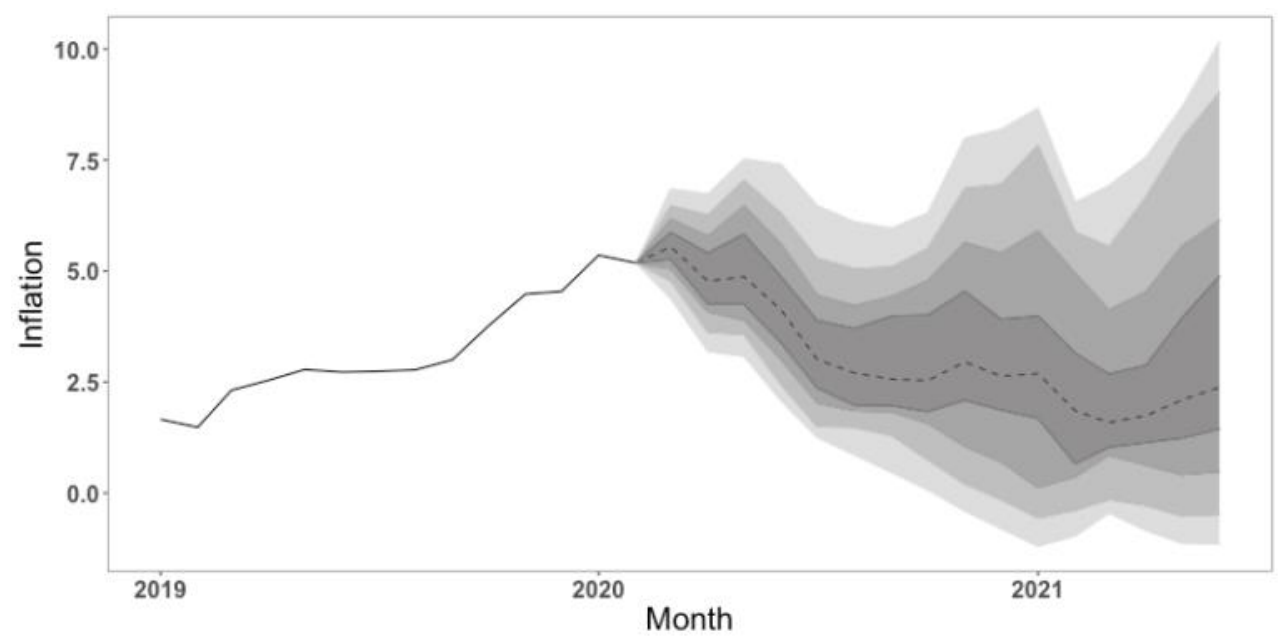

Figure 1. Inflation forecasting fan charts

Note. The figure shows the distribution forecast of future inflation. The dotted line represents the predicted value at $50^{t h}$ percentile. The grey solid lines from bottom to top denote the predicted values at $5^{\text {th }}, 10^{\text {th }}, 20^{\text {th }}, 30^{\text {th }}, 50^{\text {th }}, 70^{\text {th }}, 80^{\text {th }}$, $90^{\text {th }}$, and $95^{\text {th }}$ percentile, respectively. The shadow area means that there is a $90 \%$ possibility that future inflation will fall into the overall shadow range shown in the graph. The probability represented by dark to light shaded bands is $40 \%, 60 \%, 80 \%$ and $90 \%$ respectively.

\section{Conclusions}

Based on two dimensions of system risk, this paper studies the changes in the future inflation risk level, and uses the out-of-sample quantile $R^{2}$ to further evaluate the predictive accuracy of different systemic risk indicators on inflation risk. Firstly, we compute two systemic risk indicators, MES and volatility, with data of Chinese financial institutions, which measure individual risk and financial sector volatility. And then we explore the amplification effect of these indicators on future inflation risk, under the framework of quantile regression. Finally, we predict the distribution of inflation in China from March 2020 to June 2021, and visually show the distribution trend of future inflation with forecast fan charts.

We get the following conclusions: Firstly, our results show that the introduction of systemic risk indexes can improve the prediction accuracy of the quantile regression model of inflation risk. By comparing the out-of-sample quantile $R^{2}$ of different systemic risk indicators, we find that indicator that reflects institution-specific risk can better predict future deflation risk, while volatility index has a stronger ability to predict inflation risk. Secondly, the indicators reflecting individual risk and financial sector volatility have an amplification effect on both inflation and deflation risk significantly, while the results of OLS regression model show that such impact is not statistically significant. The results of quantile regression model, conditional on systemic risk indicators, show that as systemic risk rises, the risk of inflation or deflation will increase in the 
future, which is mainly reflected in the lag of 6 to 12 . To be specific, when the overall risk of financial market rises, the extremely lower percentile of the inflation distribution tends to move to the left significantly, while the upper percentile of the inflation distribution tends to significantly move to the right. Thirdly, according to the value of the regression coefficients, it can be seen that compared with the volatility index, the MES index, which captures the individual risk of the organization, have a greater impact on the future inflation risk. While indicator that measures volatility in financial markets has more influence on the extreme lower tail of inflation rates. Finally, based on the above model, we predict Chinese inflation risk from March 2020 to June 2021, and demonstrate the future distribution of inflation with forecast fan charts. The results show that within the forecast interval of this article, China's inflation risk will rise significantly.

According to the research results of this article and Chinese national conditions, we propose the following policy recommendations: Firstly, as the relationship between financial market and real economy is getting closer and closer, we should pay more attention to the influence of financial market risk in future deflation and inflation risk. Macroeconomic departments should step up supervision of the financial system, formulate clear macro-prudential policies, adjust interest rates in a timely manner, and carry out necessary capital supervision. When certain institutions expose risk in the financial system, they should take actions to provide assistance and support to these institutions. The purpose of this approach is not to protect specific institutions from bankruptcy, but to prevent risk from spreading throughout financial system, which in turn has a negative spillover effect on the real economy.

Secondly, predict China's future inflation risk and disclose information about it regularly, with the real-time transaction data in financial markets. The regression results in this paper show that, based on the OLS regression model, financial market risk has no significant effect on the average level of inflation. Therefore, point estimates based on systemic risk indicators will underestimate the negative spillover effects of financial markets on inflation risk. In recent years, there have been central banks in some countries, such as the Bank of England, which have begun to regularly report the forecast of future inflation distribution, so that government can implement macro policies in advance to prevent widespread inflation which will damage social welfare seriously. Following the practices of these countries, China can gradually begin to predict the risk of inflation.

\section{References}

Acharya, V., Engle, R., \& Richardson, M. (2012). Capital shortfall: A new approach to ranking and regulating systemic risks. American Economic Review, 102(3), 59-64. https://doi.org/10.1257/aer.102.3.59

Adrian, T., \& Brunnermeier, M. K. (2016). CoVaR. American Economic Review, 106(7), 1705-1741. https://doi.org/10.1257/aer.20120555

Amihud, Y. (2002). Illiquidity and stock returns: cross-section and time-series effects. Journal of Financial Markets, 5(1), 31-56. https://doi.org/10.1016/S1386-4181(01)00024-6

Brownlees, C., \& Engle R. (2011). Volatility, correlation and tails for systemic risk measurement. Working Paper, NYU. https://doi.org/10.2139/ssrn.1611229

Cecchetti, S. G., \& Li, H. (2008). Measuring the Impact of Asset Price Booms Using Quantile Vector Autoregressions. Brandeis University Working Paper Series, 2, 1-48.

Chen, S. D., \& Wang, M. (2011). Study on Stability of China's Banking System. The Journal of Quantitative \& Technical Economics, 28(10), 64-77. https://doi.org/10.1017/S1477175611000121

Ernst, E., Semmler, W., \& Haider, A. (2016). Debt deflation, financial market stress and regime change: Evidence from Europe using MRVAR. ZEW Discussion Papers, No. 16-030. https://doi.org/10.2139/ssrn.2765411

Giglio, S., Kelly, B. T., Pruitt, S. (2016). Systemic risk and the macroeconomy: An empirical evaluation. Journal of Financial Economics, 119(3), 457-471. https://doi.org/10.1016/j.jfineco.2016.01.010

Guo, Z. Y. (2017). How Information Is Transmitted Across the Nations? An Empirical Investigation of the US and Chinese Commodity Markets. Global Journal of Management and Business Research, 17(1), 1-11. https://doi.org/10.2139/ssrn.3013797 


\section{Appendix A. Out-of-sample $R^{2}$ for robustness test}

Table A1. Out-of-Sample Forecast Accuracy (PPI) for lower quantile: $\tau=0.1$

\begin{tabular}{cccccc}
\hline & $\mathrm{h}=1$ & $\mathrm{~h}=3$ & $\mathrm{~h}=6$ & $\mathrm{~h}=9$ & $\mathrm{~h}=12$ \\
\cline { 2 - 5 } Out of sample starting time & volatility & volatility & volatility & volatility & volatility \\
\hline 2012 & 0.995 & 0.534 & 1.830 & 0.639 & 5.380 \\
2013 & 3.798 & 0.906 & 2.545 & 1.367 & 6.949 \\
2014 & 2.959 & 0.105 & 4.678 & 1.844 & 8.508 \\
2015 & 7.480 & 12.146 & 0.297 & 0.047 & 3.606 \\
2016 & 1.027 & 14.479 & 0.319 & 3.931 & 1.647 \\
2017 & 1.659 & 6.554 & 0.087 & 0.556 & 0.086 \\
\hline
\end{tabular}

Note. The table reports out-of-sample quantile $R^{2}$ (in percentage) relative to the historical quantile model. $\mathrm{h}=1,3,6,9$ and 12 represent lags of 1 month, 3, 6, 9 and 12 months, respectively. For the PPI inflation rate, 10-\% quantile regressions are run on the lagged systemic risk index volatility.

Table A2. Out-of-Sample Forecast Accuracy (PPI) for lower quantile: $\tau=0.2$

\begin{tabular}{cccccc}
\hline & $\mathrm{h}=1$ & $\mathrm{~h}=3$ & $\mathrm{~h}=6$ & $\mathrm{~h}=9$ & $\mathrm{~h}=12$ \\
\cline { 2 - 5 } Out of sample starting time & volatility & volatility & volatility & volatility & volatility \\
\hline 2012 & 1.389 & 0.631 & 0.127 & 1.875 & 6.335 \\
2013 & 1.415 & 1.320 & 0.289 & 3.751 & 7.135 \\
2014 & 1.160 & 0.959 & 0.774 & 4.330 & 7.458 \\
2015 & 5.352 & 6.156 & 0.210 & 1.425 & 1.205 \\
2016 & 0.182 & 5.790 & 0.541 & 7.702 & 1.101 \\
2017 & 1.528 & 6.585 & 0.120 & 0.103 & 1.518 \\
\hline
\end{tabular}

Note. The table reports out-of-sample quantile $R^{2}$ (in percentage) relative to the historical quantile model. $\mathrm{h}=1,3,6,9$ and 12 represent lags of 1 month, 3, 6, 9 and 12 months, respectively. For the PPI inflation rate, 20-\% quantile regressions are run on the lagged systemic risk index volatility.

Table A3. Out-of-Sample Forecast Accuracy (PPI) for higher quantile: $\tau=0.8$

\begin{tabular}{|c|c|c|c|c|c|}
\hline & $\mathrm{h}=1$ & $\mathrm{~h}=3$ & $\mathrm{~h}=6$ & $\mathrm{~h}=9$ & $\mathrm{~h}=12$ \\
\hline Out of sample starting time & volatility & volatility & volatility & volatility & volatility \\
\hline 2012 & 4.794 & 3.255 & 0.090 & 1.154 & 2.335 \\
\hline 2013 & 5.002 & 3.530 & 1.972 & 5.609 & 2.360 \\
\hline 2014 & 6.973 & 5.312 & 8.869 & 13.047 & 3.032 \\
\hline 2015 & 9.049 & 12.445 & 21.933 & 25.460 & 6.373 \\
\hline 2016 & 6.699 & 15.105 & 18.691 & 19.898 & 4.211 \\
\hline 2017 & 1.767 & 3.431 & 5.822 & 10.481 & 3.631 \\
\hline
\end{tabular}

Note. The table reports out-of-sample quantile $R^{2}$ (in percentage) relative to the historical quantile model. $\mathrm{h}=1,3,6,9$ and 12 represent lags of 1 month, 3, 6, 9 and 12 months, respectively. For the PPI inflation rate, 80-\% quantile regressions are run on the lagged systemic risk index volatility.

\section{Appendix B. The predicted value of CPI inflation rate}

Table B1. CPI Inflation Risk (\%) Forecast

\begin{tabular}{cccccc}
\hline Forecast Horizon & $\boldsymbol{\tau}=\mathbf{0 . 0 5}$ & $\boldsymbol{\tau}=\mathbf{0 . 1}$ & $\boldsymbol{\tau}=\mathbf{0 . 2}$ & $\boldsymbol{\tau}=\mathbf{0 . 3}$ & $\boldsymbol{\tau}=\mathbf{0 . 5}$ \\
\hline 2020.3 & 4.377 & 4.774 & 5.050 & 5.260 & 5.548 \\
2020.4 & 3.189 & 3.622 & 4.077 & 4.254 & 4.771 \\
2020.5 & 3.079 & 3.565 & 3.893 & 4.251 & 4.873 \\
2020.6 & 2.072 & 2.442 & 3.004 & 3.378 & 4.120 \\
2020.7 & 1.254 & 1.495 & 2.028 & 2.364 & 3.009 \\
2020.8 & 0.859 & 1.477 & 1.847 & 1.978 & 2.704 \\
2020.9 & 0.464 & 1.294 & 1.826 & 1.968 & 2.566 \\
2020.10 & 0.073 & 0.751 & 1.568 & 1.832 & 2.533 \\
2020.11 & -0.407 & 0.200 & 1.048 & 2.089 & 2.950 \\
2020.12 & -0.801 & -0.148 & 0.702 & 1.870 & 2.634 \\
2021.1 & -1.200 & -0.563 & 0.120 & 1.683 & 2.688 \\
2021.2 & -0.967 & -0.389 & 0.362 & 0.660 & 1.854 \\
2021.3 & -0.453 & -0.149 & 0.850 & 1.032 & 1.589 \\
2021.4 & -0.847 & -0.284 & 0.625 & 1.136 & 1.744 \\
2021.5 & -1.134 & -0.523 & 0.405 & 1.237 & 2.098 \\
2021.6 & -1.146 & -0.487 & 0.476 & 1.444 & 2.380 \\
\hline
\end{tabular}

Note. The systemic risk measurement index is volatility index. 
Table B2. CPI Inflation Risk (\%) Forecast (Continued)

\begin{tabular}{ccccc}
\hline Forecast Horizon & $\tau=0.7$ & $\tau=0.8$ & $\tau=0.9$ & $\tau=0.95$ \\
\hline 2020.3 & 5.871 & 6.168 & 6.472 & 6.851 \\
2020.4 & 5.405 & 5.790 & 6.263 & 6.738 \\
2020.5 & 5.831 & 6.466 & 7.052 & 7.525 \\
2020.6 & 4.866 & 5.610 & 6.302 & 7.405 \\
2020.7 & 3.888 & 4.457 & 5.290 & 6.480 \\
2020.8 & 3.705 & 4.224 & 5.055 & 6.110 \\
2020.9 & 3.989 & 4.427 & 5.092 & 5.966 \\
2020.10 & 4.006 & 4.782 & 5.508 & 6.308 \\
2020.11 & 4.544 & 5.647 & 6.870 & 7.997 \\
2020.12 & 3.918 & 5.406 & 6.953 & 8.195 \\
2021.1 & 3.986 & 5.906 & 7.837 & 8.671 \\
2021.2 & 3.153 & 4.955 & 5.879 & 6.551 \\
2021.3 & 2.681 & 4.122 & 5.557 & 6.924 \\
2021.4 & 2.879 & 4.539 & 6.674 & 7.570 \\
2021.5 & 3.948 & 5.565 & 8.002 & 8.695 \\
2021.6 & 4.880 & 6.142 & 9.022 & 10.161 \\
\hline
\end{tabular}

\section{Copyrights}

Copyright for this article is retained by the author(s), with first publication rights granted to the journal.

This is an open-access article distributed under the terms and conditions of the Creative Commons Attribution license (http://creativecommons.org/licenses/by/4.0/). 